CDD: 370.1

\title{
BENTHAM E A EDUCAÇÃO: UM PROJETO SOCIAL
}

\author{
BENTHAM AND EDUCATION: A SOCIAL PROJECT
}

Sílvio César Moral Marques ${ }^{1}$

RESUMO: No século XIX, os teóricos da teoria utilitarista pretendiam a reforma da sociedade através da adoção do princípio da "maior felicidade para o maior número" (princípio da utilidade), conforme fora proposto por Jeremy Bentham; este autor também preconizou a educação como um dos meios para atingir estas mudanças sociais. Neste artigo buscam-se reconstruir pressupostos centrais da teoria benthamita expressos em alguns textos, quais sejam, A fragment on the government, Introduction to the principles of morals and legislation e Panopticon, os quais culminam no projeto educacional sinalizado na obra Chrestomathia, explorando-os no que se refere aos objetivos pedagógicos de Bentham. A metodologia utilizada consiste na revisão bibliohistoriográfica. Os resultados e as conclusões indicam que o projeto educacional de Bentham ainda não foi suficientemente analisado por autores posteriores, apesar de sua influência.

PALAVRAS-CHAVE: Jeremy Bentham. Filosofia da educação. História da Educação.

ABSTRACT: In the nineteenth century, the utilitarian theorists wanted the reform of society by adopting the principle of "the greatest happiness for the greatest numbers" (principle of utility), as proposed by Jeremy Bentham, form which also advocated education as one of the means to achieve these social changes. In this article we attempt to reconstruct central assumptions of Bentham's theory expressed in his texts, namely A fragment on the government, Introduction to the principles of morals and legislation and Panopticon, which culminate in the educational project signaled in Chrestomathia. The methodology consists in historiographical review. The results and conclusions indicate that Bentham's educational project of has not been sufficiently considered by later authors despite their influence.

KEYWORDS: Jeremy Bentham. Philosophy of education. History of education.

\footnotetext{
${ }^{1}$ Doutor em Filosofia, Professor do Departamento de Geografia, Turismo e Humanidades da Universidade Federal de São Carlos - campus Sorocaba - Sorocaba, SP - Brasil - E-mail: silviocmm@ufscar.br Recebido em: 16/04/2012 - Aprovado em: 03/11/2012.
}

\begin{tabular}{|l|l|l|l|l|l|l|}
\hline (C) ETD-Educ. temat. digit. & Campinas, SP & v.15 & n.1 & p.1-15 & jan./abr. 2013 & ISSN 1676-2592 \\
\hline
\end{tabular}




\section{INTRODUÇÃO}

Para o exercício de qualquer uma das profissões eruditas, Direito, Medicina, ou Teologia, não há dúvida de que o conhecimento de línguas mortas, a saber, os clássicos latim e grego, pode ser considerado como uma questão antes de necessidade, do que de simples uso. Mas para um jovem destinado ao exercício de qualquer uma dessas profissões elevadas, este sistema de ensino* não foi concebido, e no caso de qualquer pessoa a ele destinado, os pais devem dignar-se em dar o aceite ao tipo de instrução aqui oferecida, e o que resta de tempo alocar-se-á em um curso de preparação para aquelas profissões, o que proverá amplo espaço para uma instrução adicional relativamente necessária a tais questões. (Jeremy Bentham, Chrestomathia, 1843, p. 17)

*i.e., a crestomathia

A segunda metade do século XVIII e a primeira metade do século XIX foram, como poucas outras épocas, períodos de intensas mudanças nas estruturas sociais: a revolução industrial proporcionou a transformação de um mundo agrário e rural em mecanizado e urbano; e as revoluções francesa e americana alteraram concepções políticas, introduzindo novas práticas que caminhavam em direção a modelos mais participativos e a novos ordenamentos jurídicos, em detrimento dos sistemas nobiliárquicos centralizados e, via de regra, arbitrários.

Este "novo mundo" solicitava novos homens: os artesãos se converteram no proletariado. Os processos fabris manuais, que levavam anos para serem aprendidos, foram substituídos pelas máquinas operadas por pessoas que necessitavam de novos conhecimentos e habilidades, diferentes daquelas do artífice: elementos que eram estranhos a tudo aquilo que fora ensinado até então. Não somente no âmbito fabril essas alterações foram observadas; nas universidades surgiam a cada momento novos campos de saberes: Isaac Newton não era mais um "filósofo natural", mas um "físico"; Charles Darwin não era mais um naturalista, tornando-se um "biólogo", etc.

Em toda a sociedade se observaram as mudanças causadas por essas duas revoluções principais, e o mesmo não tardou a ocorrer na filosofia e, logo a seguir, na educação. Foi nesse contexto que se observou, na Inglaterra, o surgimento de uma teoria que vislumbrava a 
reforma social através da adoção do princípio moral da "maior felicidade para o maior número de pessoas" (princípio da utilidade), cujo proponente foi Jeremy Bentham.

A reforma que os utilitaristas (também chamados de "radicais"2) advogavam dizia respeito à defesa do liberalismo (destacadamente o econômico), à fé na razão e ao governo representativo, o que, naquele período, principalmente na Inglaterra, era entendido como concepções sociais bem distantes das ideologias hegemônicas.

Ocorre que, para a viabilização dessas profundas alterações sociais e econômicas, Bentham e seus seguidores defendiam a mudança da sociedade pela reforma das instituições, reforma esta que, obrigatoriamente, passaria pela educação. Daí postularem mudanças nos modelos e nos currículos das escolas para crianças e adolescentes e, até mesmo, a criação de uma universidade (University of London, fundada por amigos e seguidores de Bentham em 1825 e, em 1836, renomeada como University College), na qual se oferecia um currículo que incluía artes liberais, ciências e línguas modernas; excluía o ensino de questões religiosas; e permitia a entrada de pessoas pertencentes a grupos sociais que eram segregados nas Universidades de Oxford e Cambridge.

Como teórico desse grupo, Jeremy Bentham é principalmente associado com as concepções utilitaristas, isto é, a criação de uma teoria ética consequencialista, a qual, especialmente em Bentham, abarca não somente a moral, mas também a economia, a política e o direito. Esse "sistema moral", o qual não se limitaria somente às avaliações das ações no seu aspecto individual, mas também em outros campos de atuação, pode ser rastreado ao longo das obras deste autor ${ }^{3}$ : fez uma tentativa de subsidiar a crítica do direito e da legislação de sua época, em seu primeiro livro A fragment on the government (1776); depois, dedicou-se a uma teoria moral (ética) e política, em Introduction to the principles of morals and legislation (1789), voltando-se à economia com Defense of usury (1791). Também se debruçou sobre o tema da correção moral e social, com o Panopticon (primeira versão de 1791); e, por fim, pode-se encontrar uma proposta pedagógica na Chrestomathia (1817).

\footnotetext{
2 A compreensão do utilitarismo como filosofia radical ocorre pelo fato de que criticam a sociedade nas suas estruturas de poder e de privilégios, além das instituições sociais. Sobre este assunto, ver Plamenatz (1949) e Halévy (1970).

3 A estimativa é de que as obras completas de Bentham contenham mais de cem mil páginas, as quais vêm sendo publicadas desde 1968 pela University College London, com a previsão de publicação de quase 70 volumes (atualmente a coleção está no $28^{\circ}$ volume).

\begin{tabular}{|c|c|c|c|c|c|c|}
\hline (c) ETD-Educ. temat. digit. & Campinas, SP & $\mathrm{v} .15$ & n. 1 & p.1-15 & jan./abr. 2013 & ISSN 1676-2592 \\
\hline
\end{tabular}
}


Todos estes livros culminariam na obra Constitutional Code, de 1830, a qual é considerada por muitos como o ápice de sua vida intelectual, ao propor, na forma de uma codificação, as suas ideias e concepções com seus respectivos fundamentos e justificativas. Aqui não se buscará analisar a obra de Bentham como um todo ${ }^{4}$, mas, sim, sua concepção de educação; para tanto, é necessário compreender que esta não se encontra deslocada do restante da obra: ao contrário, sua pedagogia é parte integrante de um sistema maior. No intuito de vislumbrar essas relações, é apresentado, a seguir um breve esboço dos temas centrais dos livros A fragment on the government, Introduction to the principles of morals and legislation e do Panopticon, para que, a partir dessas análises, se possa compreender a questão da educação inserida no sistema benthamita.

\section{SISTEMA SOCIAL DE BENTHAM}

O projeto de Bentham para um sistema social, cujo fundamento repousaria sobre o princípio de utilidade, teve início na obra A fragment on Government, a qual é geralmente apresentada como o exame e a crítica dos Commentaries on the laws of England, de William Blackstone ${ }^{5}$. Nela surgem os primeiros esboços das teorias desenvolvidas posteriormente. Nestes fragmentos, Bentham analisa um trecho da obra em que Blackstone discorre sobre o estabelecimento do governo, suas formas, o direito de estabelecimento de leis, notadamente naquilo que diz respeito à Inglaterra. Especificamente, Bentham criticou a posição de Blackstone contra reformas e melhorias legais, pois sustentava:

O período em que vivemos é uma época agitada, na qual o conhecimento está avançando rapidamente em direção à perfeição. No mundo natural, em particular, todos os assuntos estão repletos de descobertas e melhorias. Têm-se percorrido as regiões mais distantes e recônditas da terra e explorado todos os seres viventes e os elementos sutis do ar que foram analisados recentemente e conhecidos por evidências marcantes, como se esperava desta agradável exatidão. O correspondente da descoberta e melhoria no mundo natural, é uma reforma na moral; [...]. (BENTHAM, 1844a, p. 3)

Dessa forma, a proposta de Blackstone estaria reforçando uma concepção de mundo em desacordo com aquela observada na evolução do conhecimento da época; daí a crítica de

\footnotetext{
Para uma análise detalhada das relações entre as diferentes partes da obra de Bentham, ver Picoli (2007).

Willian Blackstone foi um jurista britânico no século XVIII, tendo publicado em 1765 o influente Commentaries on the Laws of England, texto este que foi criticado por Bentham no A fragment on government.

\begin{tabular}{l|l|l|l|l|l|l}
\hline (C) ETD-Educ. temat. digit. & Campinas, SP & v.15 & n.1 & p.1-15 & jan./abr. 2013 & ISSN 1676-2592 \\
\hline
\end{tabular}
}


Bentham e a proposta de reformas. Esse novo modelo de mundo necessitaria de um outro fundamento legal, político, econômico e moral, o qual deveria levar em consideração:

[...] talvez entre as observações que serviriam para ser melhor calculadas como a base para a reforma, estão algumas que, sendo a observação de questões de fato até agora percebidas incompletamente, ou nem consideradas, quando produzidas, parecem ser capazes de carregar o nome de descobertas: com tão pouco método e precisão obter as conseqüências deste axioma fundamental, da maior felicidade para o maior número, que é a medida do certo e do errado, tanto quanto foi desenvolvido. (BENTHAM, 1844a, p. 3).

O princípio da "maior felicidade para o maior número de indivíduos", o qual posteriormente será o cerne do utilitarismo, se apresenta como o padrão a ser observado no julgamento das ações ${ }^{6}$ e, no caso de Bentham, como um elemento norteador que pode ser aplicado na reforma de toda e qualquer instituição, a saber: o estado, as leis, as prisões, as casas de trabalho (workhouses) e as escolas.

A defesa da utilidade como o elemento que deve ser empregado no julgamento das ações e no desejo das instituições encontra sua expressão na obra Introduction to the principles of morals and legislation, na qual Bentham apresenta, segundo Picoli (2007), quatro temas centrais de discussão: a) apresentação e defesa do princípio de utilidade; b) teoria das dores e dos prazeres; c) teoria da ação; e d) teoria das ofensas e da punição.

O início da obra de Bentham possivelmente é uma das citações mais lembradas deste autor: "a natureza colocou o gênero humano sob o domínio de dois senhores soberanos: a dor e o prazer. Somente a eles compete apontar o que devemos fazer, bem como determinar o que na realidade faremos" (BENTHAM, 1973, p. 1, grifo do autor). É na percepção desses dois elementos que Bentham funda sua empresa: os seres humanos agem de modo inexorável, movidos exclusivamente pelas percepções de dor e de prazer, isto é, são elas que geram nos seres humanos as impressões e as paixões que estão na base dos sentimentos ${ }^{7}$ e, portanto, nas ações. Ocorre que, ligado a essa constatação sensualista, Bentham sustenta que "o princípio de utilidade reconhece esta sujeição e a coloca como fundamento desse sistema, cujo objetivo consiste em construir o edifício da felicidade através da razão e da lei” (BENTHAM, 1973, p. 1 , grifo do autor).

6 Sobre este assunto, ver o capítulo V, de Marques (2005).

7 Sobre este ponto, ver Hume (1998).

\begin{tabular}{l|l|l|l|l|l|l}
\hline (C) ETD-Educ. temat. digit. & Campinas, SP & v.15 & n.1 & p.1-15 & jan./abr. 2013 & ISSN 1676-2592 \\
\hline
\end{tabular}


Assim, o útil, a utilidade como critério de demarcação para direcionar as ações assenta-se numa percepção física humana: deve-se buscar o prazer e evitar a dor. Neste caso, entende-se por princípio de utilidade

aquele princípio que aprova ou desaprova qualquer ação, segundo a tendência que tem a aumentar ou a diminuir a felicidade da pessoa cujo interesse está em jogo, ou, o que é a mesma coisa em outros termos, segundo a tendência a promover ou a comprometer a referida felicidade. Digo qualquer ação, intencionando dizer que isto vale não somente para qualquer ação de um indivíduo particular, mas também de qualquer ato ou medida de governo. (BENTHAM, 1973, p. 10)

Observe-se que o princípio de utilidade deve, então, ser procurado não somente nas ações dos indivíduos, mas também nas de governo - isto é, para um coletivo: daí sua extensão para instituições sociais como a escola. Como observa Picoli, isso implica em que

[...] se, no plano dos sentimentos, o princípio da utilidade é o princípio psicológico pelo qual se explica o sentimento de aprovação moral, no plano do entendimento, ele significa um princípio ou um critério por meio do qual podemos determinar, definir, ordenar e sistematizar as distinções e os aspectos relevantes que devem ser considerados numa deliberação moral. (PICOLI, 2007, p. 135).

Tal deliberação implica em uma ética na qual a felicidade é seu ponto central: se a felicidade concerne apenas ao indivíduo e não afeta a felicidade de nenhum outro, então se considerem somente os próprios interesses; se afeta a felicidade dos demais, observem-se os interesses de todos os afetados. Mas, no campo público, o princípio da utilidade também deve ser buscado, e, neste caso,

quanto aos demais seres humanos, a arte de dirigir suas ações para o fim superior é o que queremos dizer, ou pelo menos a única coisa a qual, sob o princípio da utilidade, devemos dizer, pela arte do governo: o que, na medida em que o projeto que se apresenta é de natureza permanente, é geralmente expresso pelo nome de legislação: do mesmo modo que o é por administração, quando são de natureza temporária, determinada pelas ocorrências do dia. (BENTHAM, 1844b, p. 123, itálicos do autor).

A percepção de que as ações do governo são morais e, portanto, guiadas para a felicidade pelo princípio de utilidade produz esta interessante distinção legal aplicada por Bentham: a legislação e a administração que regulam a vida em sociedade para que se possa alcançar a felicidade. Aqui se apresenta um dos temas mais controversos na teoria de Bentham: o cálculo da dor e do prazer (cálculo felicífico). O problema é saber a quantidade de felicidade (prazer) ou infelicidade (dor) que deve ser levada em consideração para a escolha da ação mais adequada, tanto no nível individual, quanto no coletivo. Para tanto, Bentham sustenta que

\begin{tabular}{l|l|l|l|l|l|l}
\hline (C) ETD - Educ. temat. digit. & Campinas, SP & v.15 & n.1 & p.1-15 & jan./abr. 2013 & ISSN 1676-2592 \\
\hline
\end{tabular}


há quatro fontes distintas a partir das quais o prazer e a dor estão fluindo: considerados separadamente, eles podem ser chamados de física, a política, a moral e a religiosa: e na medida em que os prazeres e dores que pertencem a cada um deles são capazes de oferecer uma forte ligação com qualquer lei ou regra de conduta, a todos eles se pode denominar sanções. (BENTHAM, 1844b, p. 16, grifos do autor)

Seguindo esta linha de raciocínio, o autor estabelece os elementos que devem ser observados no curso da escolha das ações: 1) intensidade; 2) duração; 3) certeza ou incerteza; 4) proximidade; 5) fecundidade; 6) pureza; e 7) tendência. Esta lista de procedimentos, quando aplicada às ações do governo, estabelece critérios de escolha para implementação das políticas públicas. Vem daí a preocupação de Bentham com a arte da administração, que seria o estabelecimento de ações e procedimentos sociais que possibilitem a felicidade do maior número de pessoas e a correção das ações que gerem a dor. Nessa avaliação das ações que afetam a felicidade dos outros, desempenha papel central o estabelecimento de mecanismos de controle e correção das ações, isto é, a inspeção, e é este o propósito moral e legal do Panopticon $^{8}$, o qual,

\begin{abstract}
para dizer tudo em uma palavra, ele será aplicável, eu acho, sem exceção, a todo e qualquer estabelecimento, no qual, dentro de um espaço não muito grande para ser fechado ou disposto por edifícios, um número de pessoas destine-se a ser mantido sob inspeção. Não importa o quão diverso, ou mesmo oposto seja o propósito: quer seja a de punir o incorrigível, guardar o insano, reformar o viciado, confinar o suspeito, empregar o ocioso, manter o indefeso, curar o doente, instruir o aprendiz em qualquer ramo da indústria, treinar a classe em ascensão no caminho da educação: em uma palavra, que seja aplicado aos propósitos das prisões perpétuas no corredor da morte, ou prisões para confinamento antes do julgamento, ou penitenciárias, casas de correção, ou casas de trabalho, ou manufaturas, ou sanatórios, ou hospitais, ou escolas. (BENTHAM, 1843a, p. 1, itálicos do autor)
\end{abstract}

Surge, assim, o "princípio de inspeção", o qual pressupõe que

\begin{abstract}
é óbvio que, em todos esses casos, quanto mais constantemente as pessoas a serem inspecionadas estão sob os olhos daqueles que devem inspecioná-los, mais perfeitamente foi alcançado o objetivo do estabelecimento. Perfeição ideal, se for esse o propósito, necessita que a pessoa deva realmente ficar nessa situação o tempo todo. Sendo impossível, o desejável é que a cada instante tenha motivos para crer ao máximo, não sendo capaz de conceber o contrário além de imaginar a si mesmo naquela situação. (BENTHAM, 1843a, p. 1, itálico do autor)
\end{abstract}

O "princípio de inspeção" pressupõe que o indivíduo, ao saber, ou apenas imaginar que está sob vigilância, se comporte de maneira socialmente esperada ou desejada e que a correção, ou punição, das ações sirva de exemplo para os demais. Para levar a contento essa empresa, Bentham indicou minuciosamente as formas arquitetônicas que o projeto do

8 A palavra Panopticon vem da junção de duas outras: Pan (tudo) e Opticon (observar, ver), isto é, o que tudo vê.

\begin{tabular}{l|l|l|l|l|l|l}
\hline (C) ETD-Educ. temat. digit. & Campinas, SP & v.15 & n.1 & p.1-15 & jan./abr. 2013 & ISSN 1676-2592 \\
\hline
\end{tabular}


Panopticon deveria apresentar, pois acreditava que a disposição física dos prédios e dos equipamentos possibilitasse o emprego dessa "vigilância" de modo efetivo. Daí a possibilidade da sua recomendação a toda e qualquer instituição que apresente características que se prestam à aplicação do modelo proposto: prisões, hospitais, manicômios, fábricas, escolas etc. A forma arquitetônica é semicilíndrica, com uma "torre de inspeção" instalada no meio, o que possibilita ao vigia na torre ver sem ser visto; mas, na verdade, essa forma assumir outras configurações de acordo a necessidade.

Bentham partiu do fato de que, na Inglaterra pós-Revolução Industrial, havia um elevado número de pessoas vivendo nas cidades de forma precária e miserável, situação esta que provocava sérios problemas sociais e um elevado grau de sofrimento (dor = infelicidade). Assim, para o filósofo inglês, a adoção do Panóptico, por meio dos princípios de utilidade e de inspeção, nas instituições sociais que possibilitassem sua aplicação, era racional e produziria a maior felicidade ${ }^{9}$.

Parece claro que, para Bentham, o principal destinatário desse projeto era o sistema prisional (a maior parte do texto trata, de forma detalhada, da construção, da vida e do gerenciamento de prisões), mas a carta XXI de sua correspondência trata especificamente da aplicação desse princípio às escolas. O início dessa carta questiona se seria possível, ou mesmo desejável, aplicar à escola os mesmos métodos empregados nas prisões, nos manicômios e nos hospitais. A resposta a esta indagação é que seria possível aplicar o "princípio de inspeção" ao contexto educativo de duas maneiras: a) somente nas horas de estudo; e b) o tempo todo, isto é, além dos períodos de estudo, também nos momentos de descanso, repouso e recreação. No primeiro caso, Bentham acredita que não haveria qualquer objeção à sua proposta, pois “[...] com respeito às horas de estudo, não pode, eu acho, ser somente pela vontade que elas sejam empregadas em estudar" (BENTHAM, 1843a, p. 35). Ele não acredita que o emprego de grades e outros equipamentos usuais na prisão façam sentido na escola, mas sustenta que uma arquitetura na qual o professor ficasse em um patamar superior aos alunos e estes fossem separados por divisórias ou telas tão leves quanto se deseja seria a ideal para esse tipo de instituição e para os objetivos pretendidos. Ora, neste caso, argumenta que isso acabaria com as conversas, as distrações e a preguiça, tão comumente observadas nas escolas, ao fazer com que o aluno, ao ser observado constantemente por seu professor, se concentrasse somente nos estudos.

9 Devido ao estudo de Foucault dedicado às restrições ao sujeito perpetradas pelo poder institucional, na obra Vigiar e punir (1986), Bentham tornou-se mais conhecido pelo crivo da crítica foucaultiana ao Panopticon do que pelos textos por ele escritos em seu contexto original.

\begin{tabular}{|l|l|l|l}
\hline (C) ETD -Educ, temat digit. & Campinas, SP & v.15 & $\mathrm{n} .1$
\end{tabular}

p.1-15

jan./abr. 2013

ISSN 1676-2592 
Por sua vez, na observação da aplicação do "princípio de inspeção" de modo mais amplo, Bentham tem plena noção da relutância em sua implementação por parte da maioria dos pais, pois estes acreditariam que as crianças não devem ficar o tempo todo sob o olhar de seus mestres. Contra-argumentou com uma longa lista de questões que versariam sobre o problema, sendo que, de modo retórico, termina as perguntas com a mais interessante delas, a saber:

[...] se o espírito liberal e a energia de um cidadão livre não seria trocado pela disciplina mecânica de um soldado, ou a austeridade de um monge? e se o resultado deste dispositivo altamente forjado não for a construção de um conjunto de máquinas sob a semelhança de homens? (BENTHAM, 1843a, p. 70, grifos do autor)

A resposta a esta pergunta é mais instigante ainda:

\begin{abstract}
Para dar uma resposta satisfatória a todas essas questões, que são bem interessantes, mas que nenhuma delas direciona ao ponto em questão, seria necessário recorrer de imediato à finalidade da educação. Será que a felicidade aumentaria ou diminuiria com esta disciplina? Chamem de soldados, chamem de monges, chamem de máquinas: se forem felizes, eu não me importaria. Guerras e tempestades são temas melhores para ler, mas paz e calma são melhores para desfrutar. [...]. E acho que eu entreteria você com um curso de filosofia moral, ou mesmo com um sistema de educação. A felicidade é uma coisa muito bonita para se sentir, mas muito árida para se falar; assim você pode franzir sua testa para que eu nada mais diga sobre o assunto. A única coisa que acrescentarei é que quem estabelece uma escola inspecional como princípio supremo, precisa estar muito certo sobre o professor, pois o corpo do garoto não é mais a criança de seu pai, que a sua mente será a mente de seu professor, com nenhuma outra diferença além daquela entre controle de um lado e dependência do outro. Algumas destas esplêndidas questões tenho tratado com você, e de forma mais interessante ainda Rousseau teria nos entretido com elas: nem posso imaginar que ele teria colocado seu Emílio em uma casa inspecional, mas penso que ele teria ficado contente com tal escola para sua Sophia. (BENTHAM, 1843a, p. 70, grifos do autor)
\end{abstract}

Assim, para Bentham, o princípio de inspeção aplicado de modo extensivo às várias atividades da criança é um procedimento que deveria ser adotado, pois ele geraria uma disciplina que promoveria o espírito liberal e a energia de um cidadão livre, ao contrário do que muitos acreditam: é da correção das ações que se molda a pessoa, para que esta tenha a possibilidade de ser um cidadão em sua plenitude. Aqui cabe a observação final de Bentham sobre o seu projeto de inspeção, o qual resume adequadamente as suas convicções.

O que você diria, se pela adoção progressiva e aplicação diversificada deste único princípio, você observasse um novo cenário de coisas a se espalhar sobre a face de uma sociedade civilizada? Moral reformada, saúde preservada, indústria revigorada, instrução difundida, encargos públicos justos, a economia como se estivesse assentada sobre uma rocha, e não o nó górdio das leis dos pobres não cortado, mas desatado - tudo por uma simples idéia em arquitetura? (BENTHAM, 1843a, p. 70) 


\section{Chrestomathia - UM PROJeto Pedagógico}

Bentham formou-se no que pode ser considerado como a educação tradicional inglesa no século XVIII: estudou nos primeiros anos no Westminster School, posteriormente fez o bacharelado no Queens College em Oxford e estudou direito no Lincoln's Inn. Essa educação era fortemente marcada pelos estudos dos clássicos, além de teologia, latim e grego, o que para Bentham se revelaria limitante, caso o tipo de atividade que a pessoa fosse desenvolver tivesse pouca ou nenhuma relação com esses aprendizados. É nessa percepção de que as escolas ensinariam conteúdos pouco aplicáveis (úteis), em uma sociedade que se encontrava em forte transformação, na direção da tecnologia e da ciência, que o projeto educacional de Bentham se insere.

A proposta de educação de Bentham tomou corpo a partir de 1814, com a elaboração de um projeto de escola secundária, laica, para crianças de até 14 anos, num sistema de ensino nos moldes de monitoria: alunos mais velhos ensinavam os mais novos, e um único professor podia ensinar a centenas de alunos; o currículo seria majoritariamente voltado para a ciência e a tecnologia, conhecimentos estes de utilidade para quem estava à procura de emprego na indústria e no comércio da Inglaterra do século XIX. Por fim, vale ressaltar que as instruções contidas na Tábua II do texto indicavam a necessidade de um "[...] princípio que promete $e$ garante uma inspeção constante e universal (a esse respeito emprega-se o princípio da Arquitetura Panóptica)" (BENTHAM, 1843b, p. 44 J, grifo do autor).

A execução deste projeto, que inicialmente se pretendia instalar nos jardins da casa de Bentham, não foi adiante e, em 1817, ele foi publicado sob o título de Chrestomathia ${ }^{10}$, cuja tradução seria “propício à aprendizagem útil” (BENTHAM, 1843b, p. 8).

Como em outras obras de Bentham, aqui se faz uso de tabelas (duas) para facilitar e sistematizar ao leitor o que se deseja expor. A síntese e a estrutura das obras são observadas no próprio título das tabelas:

Tabela I - Mostra os diversos ramos da INSTRUÇÃO INTELECTUAL, incluídas no curso agregado, proposto para ser realizado na escola Chrestomática: juntamente com as várias ETAPAS em que o curso proposto se divide: acompanhado de uma breve exposição das VANTAGENS derivadas de tal instrução: junto com a indicação das RAZÕES, pela ORDEM DE PRIORIDADE, aqui observado, que foi sugerida; e uma LISTA dos RAMOS DE INSTRUÇÃO OMITIDOS, com a indicação dos MOTIVOS da omissão. (BENTHAM, 1843b, p. 8 I, grifo do autor)

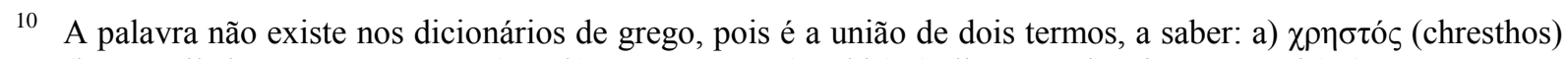
(bom, útil, honesto, que presta); e b) $\mu \alpha ́ \theta \eta \mu \alpha-\tau o \varsigma$ (mathia) (a lição, a ciência, a matéria) (MURACHCO, 2001).

\begin{tabular}{l|l|l|l|l|l|l}
\hline (C) ETD-Educ. temat. digit. & Campinas, SP & v.15 & n.1 & p.1-15 & jan./abr. 2013 & ISSN 1676-2592 \\
\hline
\end{tabular}


Tabela II - Mostra, panoramicamente, os PRINCÍPIOS constitutivos do Novo Sistema de Instrução, considerado como aplicável aos diversos ramos da Arte e Conhecimento Científico (incluindo Aprendizado de Línguas) por meio de vários tipos de EXERCÍCIOS, pelo desempenho pelo qual a Instrução Intelectual é obtida ou alcançável (BENTHAM, 1843b, p. 44 J, grifo do Autor)

Destacam-se, na Tabela II e ao longo do texto que se relaciona com ela, 38 princípios

do gerenciamento escolar a serem adotados neste sistema de ensino, a saber:

a) princípios que podem ser aplicados de modo irrestrito: 1) princípio $d a$ maximização do emprego do Professor; 2) princípio da preferência do Professor competente; 3) princípio do emprego da maximização da tutoria escolar, ou emprego do assistente de sala; e 4) princípio do emprego da maximização do Monitor escolar ou a maximização do emprego da preservação da Ordem Escolar; 5) princípio da economia do tempo do Mestre, ou Nil per se quod per suos; e 6) princípio da inspeção regular, ou proporcionar a constante Superintendência;

b) princípios específicos que objetivam disciplina etc.: 7) princípio da minimização da punição, e exclusão da Punição Corporal; 8) princípio da gratificação econômica; 9) princípio que promete e garante uma inspeção constante e universal; 10) princípio do Place-capturing ${ }^{11}$; 11) princípio da promoção da Atração (a partir do Mestre escolar); 12) princípio do Júri Penal Juvenil, ou emprego de jurados estudantis;

c) Princípios específicos que objetivam garantir a produção de evidências: 13) princípio do Registo do Progresso Conquistado, ou emprego do Registro; 14) princípio do Registro da capacidade individual e comparativa, ou emprego do registro dos resultados das competições; 15) princípio do registro das Delinquências, ou emprego do Livro Negro; 16) princípio da delação Universal, ou princípio da Convivência não tolerante ${ }^{12}$;

d) Princípios específicos que objetivam garantir a perfeição: 17) princípio da competência Universal; 18) princípio da presunção da não-idéia, ou da nãointelecção; 19) princípio da exigência de um desempenho perfeito que seja constante e universal, ou a não tolerância ao desempenho imperfeito; 20) assegurar uma progressão gradual; ou emprego gradual de exercícios progressivos; 21) princípio da exigência frequente da adequada recapitulação; 22) princípio da maximização do Place-capturing no emprego de exercícios probatórios; 23) princípio da maximização do emprego de padrão verbal, e exigência de conformidade verbal, 24) princípio da maximização do emprego de Teste de Intelecção Orgânica; 25) princípio da maximização no emprego dos testes de intelecção; 26) princípio da maximização da exigência auto-desenvolvimento; 27) princípio da descrição do trabalho solicitado e apresentação das exigências; 28) princípio da maximização da Exibição constante de Tabelas ilustradas e completamente abrangentes; 29) princípio da prevenção da Distração, ou da exclusão de objetos Exteriores; 30) princípio da classificação escolar correta pela adequação constante e universal;

e) Princípios que tenham por seu objetivo especial a união da máxima eficiência com o máximo de uniformidade; assim encurtando proporcionalmente o tempo empregado na aquisição do conteúdo proposto de instrução, e aumentando o número

11 Termo sem tradução em português, mas que se refere ao princípio de competição entre os alunos como forma de substituição das punições corporais. Neste caso, a posição (place - local em que se senta) do aluno na sala é vista como uma recompensa ou punição através da proximidade com o mestre.

12 Seria semelhante ao princípio da tolerância zero.

\begin{tabular}{l|l|l|l|l|l|l}
\hline (C) ETD-Educ. temat. digit. & Campinas, SP & v.15 & n.1 & p.1-15 & jan./abr. 2013 & ISSN 1676-2592 \\
\hline
\end{tabular}


de alunos que possam adquirir, por intermédio dos mesmos Professores, ao mesmo tempo: 31) princípio da maximização da simplificação, ou o emprego de lições curtas; 32) princípio que prometem resultados de ações simultâneas e Universais, 33) princípios que prometem resultados constantes de ações ininterruptas; 34) princípio do emprego da palavra de ordem, ou abreviação e direcionamento da fala; 35) princípio dos sinais universais visíveis, ou emprego de exemplos, ou uso universal e simultâneo de elementos visuais diretos; 36) princípio da exclusão da repetição desnecessária; 37) princípio da maximização do emprego de exercícios mnemônicos; 38) princípio do emprego de variação, ou alternância de tarefas. (BENTHAM, 1843b, passim)

Todos estes princípios indicados por Bentham visam possibilitar o desenvolvimento do conceito expresso na primeira parte de seu texto: a instrução intelectual (intellectual instruction). O filósofo inglês não explicita um conceito de instrução intelectual; entretanto, pode-se inferir a partir de sua apresentação das vantagens do aprendizado em geral e do sistema por ele proposto em particular. Quanto ao aprendizado em geral (learning or intellectual instruction), sustenta que ele é vantajoso, pois assegura ao seu possuidor: 1) respeito geral; 2) remédio contra o tédio; 3) freio da sensualidade excessiva; 4) antídoto contra o ócio; e 5) boas companhias. (BENTHAM, 1843b, passim). Hodiernamente são curiosas as razões expostas; pode-se considerá-las como uma explicação do senso comum, de um pai justificando aos seus filhos as "vantagens" da educação, no sentido mesmo de mecanismos de aceitação e ascensão social, ao invés de considerações críticas e libertadoras, de uma independência individual alcançada pela educação.

Por sua vez, as vantagens da instrução intelectual a partir do sistema proposto seriam, segundo o próprio Bentham (1843b, passim): 1) ampliação das habilidades e das áreas de conhecimento; 2) aumento da possibilidade de conseguir um emprego; 3) mente mais forte pela ampliação dos conhecimentos; 4) aplicação na atividade escolhida pela pessoa - qualquer que seja; 5) criação de hábitos desejáveis: ordem, tranquilidade e autocontrole; 6) desenvolvimento do sentimento de conforto e segurança nas variadas situações; 7) segurança na condução da vida e da saúde; 8) segurança contra terrores sem fundamento; 9) possibilidade de escolha de bons companheiros ao longo da vida; 10) oportunidade de alívio aos pais; 11) baixo custo deste sistema de ensino; 12) introdução de novos saberes úteis; 13) eliminação das punições corporais; 14) oportunidade de disputa entre os estudantes para destaques e recomendações; 15) ampliação das possibilidades da aplicação das áreas acadêmicas.

Nestas vantagens, assim como nas anteriores, observa-se uma preocupação predominante com o desenvolvimento de ocupações sociais (emprego) e com a aquisição de

\begin{tabular}{l|l|l|l|l|l|l} 
(C) ETD-Educ. temat. digit. & Campinas, SP & v.15 & n.1 & p.1-15 & jan./abr. 2013 & ISSN 1676-2592
\end{tabular}


hábitos considerados adequados socialmente. Novamente aqui parece imperar o senso comum $^{13}$. Entretanto, esta acusação de senso comum fica deslocada, ao se considerar o projeto social de Bentham: é a utilidade do processo educativo o que importa, e não elementos do conteúdo a ser ensinado. Para ele, é muito mais útil aprender sobre química que pode ser usada na vida pessoal e profissional da pessoa que irá trabalhar com isso, do que aprender latim, o qual será de mais utilidade para um advogado. Aqui se insere o problema não da qualidade, mas, sim, da quantidade: em que este conteúdo a ser aprendido contribuiria para maximizar o prazer e diminuir a dor do educando.

A instrução intelectual, para Bentham, é muito mais uma forma de busca da felicidade através da moderação e da inclusão nas estruturas sociais vigentes. Aqui Bentham está provendo um substrato teórico-pedagógico coerente com sua teoria moral e que traz para a educação os elementos do cálculo felicífico. Se isto se assemelha ao senso comum, deve-se ter em mente a advertência de John Stuart Mill:

[...] os defensores da utilidade sentem-se muitas vezes instados a responder objeções como a de que não há tempo, antes da ação, para calcular e ponderar os efeitos de uma linha de conduta sobre a felicidade geral. [...]. A resposta a essa objeção é a de que houve imenso tempo para isso, isto é, todo o passado da espécie humana. Durante todo este tempo a humanidade esteve aprendendo, pela experiência, as tendências das ações, e toda a prudência assim como a moralidade da vida dependem desta experiência. As pessoas falam como se o início desse curso de experiência tivesse sido adiado até agora, e como se, no momento em que alguém sente a tentação de interferir na propriedade ou na vida de outro tivesse que começar a considerar pela primeira vez se o assassinato e o roubo são prejudiciais à felicidade humana. Mesmo que fosse assim, não creio que essa pessoa acharia a questão muito enigmática, mas, de qualquer modo, o trabalho já está feito. (MILL, 2000, p. 48)

O que Bentham observa e propõe sobre a educação é convergente com a percepção do senso comum, pois leva em conta a experiência acumulada pelas gerações humanas; com a ressalva de que coloca esta experiência à luz do princípio de utilidade.

Como exposto, Bentham considerava que seria através da instrução intelectual com base na utilidade que se ultrapassariam as superstições oriundas principalmente da religião e das crenças populares; além dos preconceitos políticos e jurídicos profundamente enraizados na sociedade inglesa, superação esta que permitiria as reformas político-sociais por ele advogadas. Assim, a educação pela chrestomatia, como parte do projeto utilitarista, não

13 A crítica de que algumas análises de Bentham sobre as dinâmicas sociais ficariam, por vezes, no senso comum são antigas. "A Economia clássica sempre gostou de conceber o capital social como grandeza fixa com grau fixo de eficiência. Mas o preconceito só foi solidificado em dogma pelo arquifilisteu Jeremias Bentham, o oráculo insípido, pedante e tagarela do senso comum burguês do século XIX.” (MARX, 1996, p. 241).

\begin{tabular}{l|l|l|l|l|l|l}
\hline (C) ETD-Educ. temat. digit. & Campinas, SP & v.15 & n.1 & p.1-15 & jan./abr. 2013 & ISSN 1676-2592 \\
\hline
\end{tabular}


somente aumentaria o bem-estar social e econômico, mas também proporcionaria a maior felicidade do maior número de pessoas, aperfeiçoando o sistema social pela reforma da educação. Até que ponto a sociedade contemporânea acabou por endossar esta visão é assunto para uma discussão posterior, algures.

\section{REFERÊNCIAS}

BENTHAM, Jeremy. A fragment on government. London: John Bowring, 1844a.

BENTHAM, Jeremy. Uma introdução aos princípios da moral e da legislação. Trad. Luiz João Baraúna. Col. Os Pensadores. São Paulo, Abril, 1973.

BENTHAM, Jeremy. Chrestomathia. London: John Bowring, 1843 b.

BENTHAM, Jeremy. Introduction to the principles of morals and legislation. London: John Bowring, 1844b.

BENTHAM, Jeremy. Panopticon. London: John Bowring, 1843a.

FOUCALT, Michel. Vigiar e punir: nascimento da prisão. Trad. Ligia M. Ponde Vassalla. Petróplis: Vozes, 1986.

HALÉVY, Elie. Growth of philosophic radicalism. London: Augustus M. Kelley, 1970.

HUME, David. An enquiry concerning the principles of morals. Editado por Tom L. Beauchamp. Oxford: Oxford University Press, 1998.

MARQUES, Sílvio C. M. Hume: princípios e limites da moral. 2005. Tese (Doutorado) Faculdade de Filosofia, Letras e Ciências Humanas, Universidade de São Paulo, 2005.

MARX, Karl. O capital. Trad. Regis Barbosa e Flávio R. Kothe. São Paulo: Abril, 1996. (Os economistas).

MILL, John Stuart. O utilitarismo. Introd. e Trad. de Alexandre Braga Massella. São Paulo: Iluminuras, 2000.

MURACHCO, Henrique. Língua grega: visão semântica, lógica, orgânica e funcional. São Paulo: Discurso Editorial; Editora Vozes, 2001.

PICOLI, Rogério Antonio. Sobre o governo em Jeremy Bentham: o risco das partes e o traçado do todo. 2007. Tese (Doutorado) - Faculdade de Filosofia, Letras e Ciências Humanas, Universidade de São Paulo, 2007.

PLAMENATZ, John. The english utilitarians. Oxford: Basil Blackwell, 1949.

\begin{tabular}{l|l|l|l|l|l|l} 
(C) ETD-Educ. temat. digit. & Campinas, SP & v.15 & n.1 & p.1-15 & jan./abr. 2013 & ISSN 1676-2592
\end{tabular}


Como citar este artigo:

MARQUES, Sílvio César Moral. Bentham e a educação: um projeto social. ETD - Educação Temática Digital, Campinas, SP, v. 15, n. 1, p.1-15, jan./abr. 2013. ISSN 1676-2592.

Disponível em: <http://www.fae.unicamp.br/revista/index.php/etd/article/view/3039>. Acesso em: 19 abr. 2013. 